\title{
The OSEL Taxonomy for the Classification of Learning Objects
}

\author{
Vito Nicola Convertini, Diego Albanese, Agostino Marengo, \\ Vittorio Marengo, and Michele Scalera \\ Faculty of Economics - University of Bari, Bari, Italy
}

\author{
nconvertini@dss.uniba.it dalbanese@dss.uniba.it \\ amarengo@dss.uniba.it vmarengo@dss.uniba.it \\ mscalera@dss.uniba.it
}

\begin{abstract}
This project started from the necessity to create a taxonomic classification for the management of the Learning Objects (LO) repository used by the LCMS platforms. The classification obtained is now in use for the OSEL project (OSEL website - http://www.osel.it). The OSEL project is financed by the Statistics Department of the University of Bari. The aim is to analyze and to promote the introduction of blended elearning in the academic world. Many LCMSs Open-source platforms have been studied, tested and put at users' disposal. The support to the ADL/SCORM (see http://www.adlnet.org) given by all the platforms has allowed the integration in the OSEL web of the repository service, along with the services already in use (forum, newsletter, glossary, database). The aim is to gather and to catalogue the LO products proposed in the various courses and managed by the learners on the web. Starting from Wiley's (2000) and Redeker's (2003) taxonomies, the research group studied the OSEL Taxonomy and presented the project of a web application able to classify the LO and to place them in order into the repository.
\end{abstract}

Keywords: taxonomy, learning objects, OSEL, repository, SCORM

\section{Introduction}

Recently the utilization of multimedia didactics objects known as learning objects (LO) on an international scale in the planning of complex learning courses has been done using unsuitable planning methodologies that were often borrowed from the experience gained during lectures. This has lead to the ineffective use of didactic products. The frequent recourse to e-learning, together with the need to propose didactic courses that can actually give added value, requires a different approach to the planning of each didactic product and, above all, of the formative structured courses.

Actually, if universities, companies and private firms consider e-learning a fast and dynamic tool for re-

Material published as part of this journal, either on-line or in print, is copyrighted by the publisher of the Interdisciplinary Journal of Knowledge and Learning Objects. Permission to make digital or paper copy of part or all of these works for personal or classroom use is granted without fee provided that the copies are not made or distributed for profit or commercial advantage AND that copies 1) bear this notice in full and 2) give the full citation on the first page. It is permissible to abstract these works so long as credit is given. To copy in all other cases or to republish or to post on a server or to redistribute to lists requires specific permission and payment of a fee. Contact Publisher@ijklo.org to request redistribution permission. mote learning, the heterogeneous didactic goals force the instructional designer to adopt flexible and efficient methodologies for the planning and the analysis of the didactic needs.

In the e-learning planning system, the possibility to convert into graphic representations the concepts, the didactic methodologies, and the results achieved by the learners is of great importance. 
Usually the instructional designer chooses to use representation tools, such as matrix, flowcharts, mental maps (the best to represent the different branches of information and concepts directly related to a principal idea), and conceptual maps (used less frequently but undoubtedly more efficacious, and based upon the concept of multidimensional relationship). In the transposition of the conceptual map to the didactic course the organization of the Learning Objects according to a coherent and flexible taxonomy has a great importance.

\section{The OSEL Project}

The OSEL (Open Source E-Learning) project is a research project in which the aim is to create a database of Open Source Learning Content Management Systems (LCMS), to study and to compare them in order to introduce blended didactics in the academic environment.

The role of the OSEL project, financed by the University of Bari, is to point out the e-learning panorama. It addition, it offers to the registered users the chance to plan and to develop learning paths over a lot of LCMSs. The available platforms are: Moodle: 1.4.3 (http://www.moodle.org); Docebo: 2.0.0 (http://www.docebolms.org), ATutor: 1.4.2 (http://www.atutor.ca), Dokeos: 1.5.5 (http://www.dokeos.com).

All the platforms are available on the OSEL web and administrated by CMS Mambo.

Every LCMS has the following specifications:

- Access, identification and administration of users' profile. The users enter the platforms through an identification system based on profiles having different levels of authorization (i.e. teacher, learner, tutor, and administrator). The authentication is made by a unique logon so the user can enter the operations allowed to his level.

- Didactics use. This function is based on a tracking system of the relationship between the user and the platform. It is a sort of bi-directional communication that allows saving and monitoring important data on the activities made by the learner. The tracking is important in the academic courses where eventually final certifications have to be supported.

- Content management. This function allows the integration between the project and the production of contents with different tools starting from simple text editor to multimedia systems;

- Activities management. This area includes all the tools necessary to the interaction among teachers and learners, and learners as well; there are synchronous activities (i.e. chat, virtual courses, simulations and video-conference), and asynchronous activities (i.e. e-mail, forum, and other group activities).

\section{Literature Review}

The repository (http://www.remository.com) has the function to catalogue and to research the LO at user's disposal, i.e. a sort of warehouse of LO similar to a database in which the LO are registered. The great number of courses organized, which as of now are more than 60, together with the important support given to the ADSL SCORM by all the platforms proposed, made it fundamental to render the didactic materials re-usable in different situations.

This kind of activity is new in this context (excluding Merlot (http://www.merlot.org) in the United States and Didaweb in Italy) as an axiomatic use of the LO is considered as re-usable materials in the LCMSs platforms. 
The repository also works on an internal search engine. The information, i.e. the contents and the objects, are actually available within the platform, and are not hyperlinked on the Internet.

The use of the repository is a transversal support to the courses within the project and it conceptually follows the scheme by Cohen and Nycz (2006) and Varlamis \& Apostalakis (2006). See Figures 1 and 2 respectively.

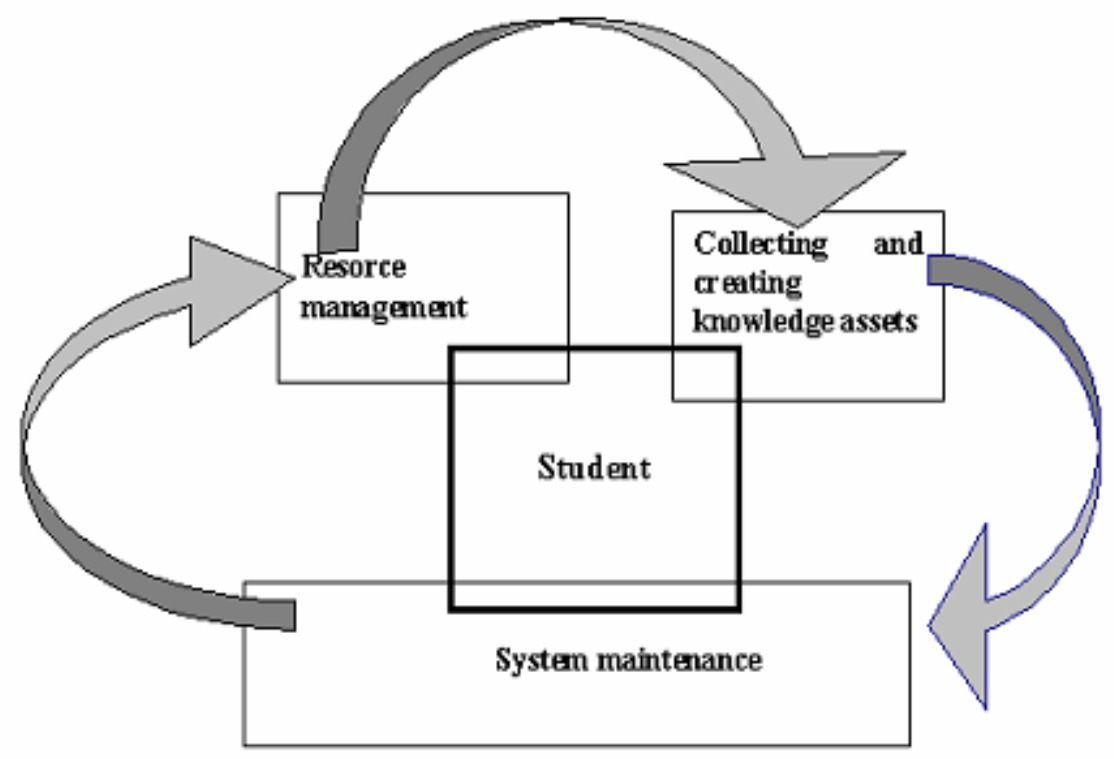

Figure 1: Learning Content Management System (Cohen \& Nycz, 2006)

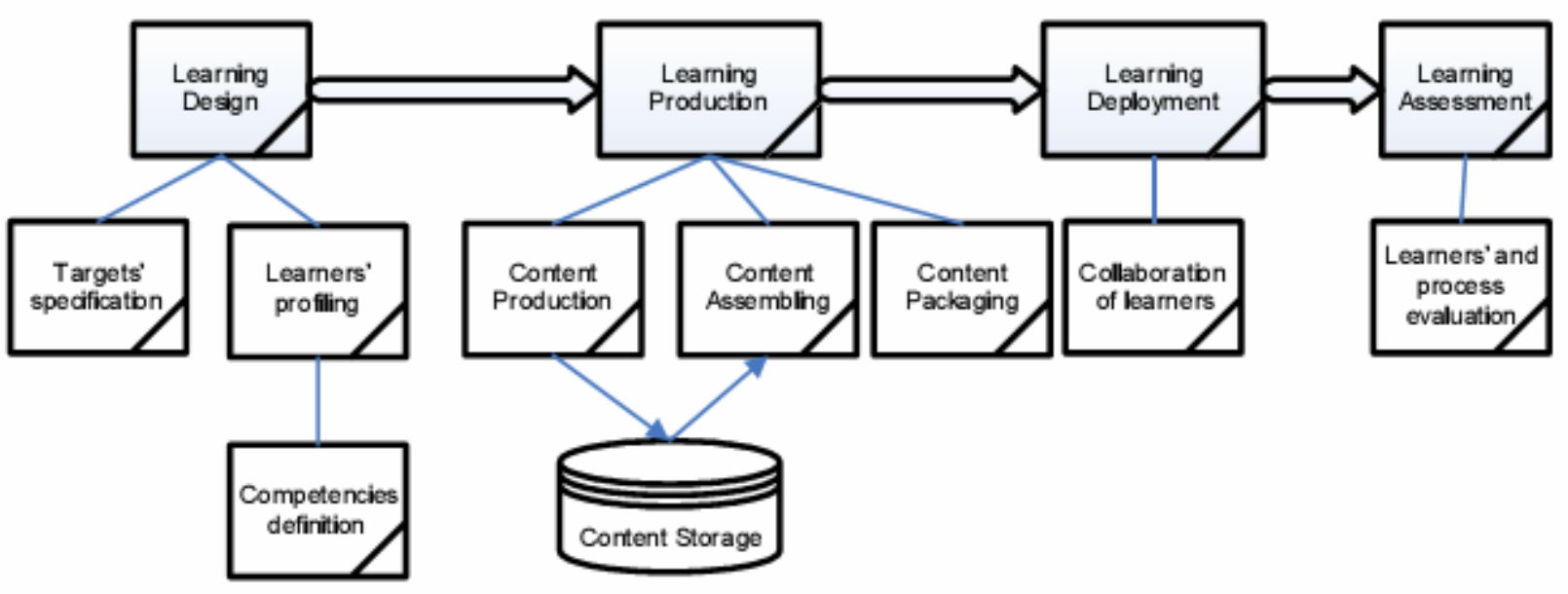

Figure 2. The life cycle of the e-Learning Process (Varlamis \& Apostalakis, 2006)

This involves the reproduction and the duplication, if allowed by license, of the didactic resources. Thus the research group decided to submit all the LO gathered in the repository to the "Common Creative Attribution 2.0 ITA" license, according to the results of the acts of the $4^{\circ}$ International Internet Education Conference (Convertini, Buonamassa, Marengo, Rossini, \& Scalera, 2005) on the specificity of use of the 
licenses, as explained on the OSEL Web Portal. The choice of a unique license is in line with point n. 9 of the Suggested Best Practices of Learning Objects (See Nash, 2005), henceforth, the explanation on how to organize a flexible directory structure able to describe the LO. The solution that the research group found has lead to the definition of a new taxonomy for the classification of LO.

Once the structures are defined the LO data entry will be ruled by software that administers the results coming from a web form. It will refer to the ADL/SCORM values, avoiding the compilation of a questionnaire.

\section{Preliminary and Ontological Remarks}

The necessity to find a flexible taxonomy for the LO has inevitably led to issues related to ontology. Recently this concept, derived from philosophy, has been introduced and used in different contexts, gaining a primary role in the Artificial Intelligence environment. Ontologies are not simple to define and difficult to apply. This is due to the difficulty of defining the Being/nature of the substratum which, in its turn, would serve to define the Being itself. Many tried to give a shape to this concept. In 1991 Neches et al. talked about ontology as the sum of the basic terms that are the basis for the vocabulary of a specific area, with the rules to combine the terms and the extensions of that vocabulary.

Starting from this point, Gruber (1993) used the term to refer to the specific value of a concept. According to him, in knowledge-based systems, only those things that actually exist can be represented. When the knowledge of a domain is represented in a declarative formalism the set of representable objects is called the universe of the discourse. The set of these objects, together with the set of the possible relationships among them, in a vocabulary of representation by which a knowledge-based software can represent a certain domain of knowledge, is called an ontology.

The introduction of ontologies in the computer science world gives a valid tool to the learning process. Above all, in the A.I. context the use of them is actually increasing for the significant role they have in information systems, in the semantic Web, and in the systems that are based on knowledge, as for instance a neural net. The recent attention the A.I. community is paying to ontologies focuses on the theories about content more than those about mechanism. Chandrasekaran, Josephson, \& Benjamins (1999) suggest that although mechanisms are important for the functioning of intelligent machines, they are useless without a good theory of content on which mechanisms must rule. Furthermore once a good theory of content is available, different mechanisms can be used to implement efficient systems ruling on the same content.

Thus the ontologies become theories of content as they contribute to identify specific sets of objects and relationships that exist in a specific domain of knowledge.

The ontological analysis clarifies the structure of the knowledge: given a certain domain its ontology is the heart of any system of representation for that domain. Ontologies are usually represented as a toxonomic tree of conceptualizations, which are general and independent from the domain at the top and become more and more specific while going down the hierarchy. In other words, the aspects which are typical of a certain domain are more visible on the taxonomic levels, which are at the bottom. One of the reasons why it is important to create and develop ontology is the possibility to share the knowledge among people or software agents. It is clear that ontologies highlight all the possible relationships among the concepts related to a domain. Once the relationships to a domain are evident, it is simpler to modify them as the knowledge of that domain becomes deeper. Moreover, it becomes simpler for new users to understand the meaning of any term used in a domain when the specifications given by the ontology are evident. The presence of a joining structure helps to avoid confusion in the use of concepts and terms. 


\section{Problem Definition}

Wiley (2000) correctly says "The discussion of learning object characteristics, such as sequence, scope, and structure, leads one to consider that different types of learning objects might exist." In other words, certain types of learning objects can be meaningfully differentiated. Taxonomy development has historically accompanied instructional design theories (Bloom, 1956; Gagne, Briggs, \& Wager, 1992) and is recommended by Richey (1986) and Nelson (1998) in their instructional design theory development approaches.

According to Richey (1986), the development of conceptual models such as taxonomies serves to "identify and organize the relevant variables: defining, explaining, and describing relationships among the variables". While object categorizations exist specific to particular instructional design theories, such as Merrill, Li, and Jones's (1991) sets of process, entity, and activity classifications, a general learning object taxonomy compatible with multiple instructional design theories does not exist.

Starting from the awareness of the lack of a universally recognized taxonomic classification, this research has been oriented to study not only the structural characteristics of any single LO but also their interoperability with the users participating, or not participating, in a group activity.

The OSEL Taxonomy is based on the two most significant taxonomies, known all over the world. The first is Wiley's (2000) taxonomy, called "Preliminary Taxonomy of Learning Object Types". It counts five kinds of LO having eight characteristics:

- Fundamental (i.e. a video of a hand typing on a keyboard );

- Combined-closed (i.e. a video of a hand typing on a keyboard with a background sound);

- Combined-open (i.e. a web page containing an image and a file containing an animation with an interactive text)

- Generative-Presentation (i.e. a java applet able to generate an html page lay-out, or to show an editor with a correspondent code or to ask questions to the learner)

- Generative-Instructional (i.e. an interface that teaches how to play an instrument)

Whereas the characteristics are:

- Number of elements combined: the number of the single elements (as video clips, images, etc.) which constitute the $\mathrm{LO}$

- Type of objects contained: the kinds of LO that can setup a new LO

- Re-usable component objects: it indicates if it is possible to have access to the different components of a LO in order to re-use them in other learning contexts

- Common function: the basic use of a LO

- Extra-object dependence: it indicates if the LO needs other information about other LO (i.e. the place on the web)

- Type of logic contained in object: it describes the function of the algorithms and the proceedings contained in the LO

- Potential for inter-contextual re-use: it indicates the number of learning contexts in which the LO can be used, i.e. its potential to be re-used

- Potential for intra-contextual re-use: it highlights the times that the LO can be re-used within the same area or domain.

Table 1 summarizes the relationships among kinds and characteristics. 
Table 1: Relationships among kinds and characteristics in Wiley's classification

\begin{tabular}{|l|l|l|l|l|l|}
\hline $\begin{array}{c}\text { Learning } \\
\text { Object } \\
\text { Characteristic }\end{array}$ & $\begin{array}{c}\text { Fundamental } \\
\text { Learning } \\
\text { Object }\end{array}$ & $\begin{array}{c}\text { Combined- } \\
\text { closed } \\
\text { Learning } \\
\text { Object }\end{array}$ & $\begin{array}{c}\text { Combined- } \\
\text { open } \\
\text { Learning } \\
\text { Object }\end{array}$ & $\begin{array}{c}\text { Generative- } \\
\text { presentation } \\
\text { Learning } \\
\text { Object }\end{array}$ & $\begin{array}{c}\text { Generative- } \\
\text { instructional } \\
\text { Learning } \\
\text { Object }\end{array}$ \\
\hline $\begin{array}{l}\text { Number of ele- } \\
\text { ments combined }\end{array}$ & One & Few & Many & Few - Many & Few - Many \\
\hline $\begin{array}{l}\text { Type of objects } \\
\text { contained }\end{array}$ & Single & $\begin{array}{l}\text { Single, Com- } \\
\text { bined-closed }\end{array}$ & All & $\begin{array}{l}\text { Single, Com- } \\
\text { bined-closed }\end{array}$ & $\begin{array}{l}\text { Single, Com- } \\
\text { bined-closed, } \\
\text { Generative- } \\
\text { presentation }\end{array}$ \\
\hline $\begin{array}{l}\text { Reusable com- } \\
\text { ponent objects }\end{array}$ & (Not applicable) & No & Yes & Yes / No & Yes / No \\
\hline $\begin{array}{l}\text { Common } \\
\text { function }\end{array}$ & Exhibit, display & $\begin{array}{l}\text { Pre-designed } \\
\text { instruction or } \\
\text { practice }\end{array}$ & $\begin{array}{l}\text { Pre-designed } \\
\text { instruction and / } \\
\text { or practice }\end{array}$ & Exhibit, display & $\begin{array}{l}\text { Computer- } \\
\text { generated in- } \\
\text { struction and / } \\
\text { or practice }\end{array}$ \\
\hline $\begin{array}{l}\text { Extra-object } \\
\text { dependence }\end{array}$ & No & No & Yes & Yes / No & Yes \\
\hline $\begin{array}{l}\text { Type of logic } \\
\text { contained in } \\
\text { object }\end{array}$ & (Not applicable) & $\begin{array}{l}\text { None, or answer } \\
\text { sheet-based item } \\
\text { scoring }\end{array}$ & $\begin{array}{l}\text { None, or do- } \\
\text { main-specific } \\
\text { instructional and } \\
\text { assessment } \\
\text { strategies }\end{array}$ & $\begin{array}{l}\text { Domain-specific } \\
\text { presentation } \\
\text { strategies }\end{array}$ & $\begin{array}{l}\text { Domain- } \\
\text { independent } \\
\text { presentation, } \\
\text { instructional, } \\
\text { and assessment } \\
\text { strategies }\end{array}$ \\
\hline $\begin{array}{l}\text { Potential for } \\
\text { inter-contextual } \\
\text { reuse }\end{array}$ & High & Medium & Low & High & High \\
\hline $\begin{array}{l}\text { Potential for } \\
\text { ntra-contextual } \\
\text { reuse }\end{array}$ & Low & Mowium & High & High \\
\hline
\end{tabular}

The second taxonomy of which the OSEL taxonomy is based on is the "Educational Taxonomy for Learning Objects" by Redeker (2003). It focuses above all on the didactics aspects related to the LO.

The LO are grouped into:

- Receptive: the learner is simply the beneficiary of the contents. Usually the learner's activity exploits LO of little dimension.

- Internally interactive: there is interaction between user and computer. The LCMS or the models created by the teacher guide the learner.

- Cooperative: containing brainstorming or problem solving sessions which require communicative activities among the students.

\section{Introductory Remarks to the OSEL Taxonomy}

The two taxonomies considered so far are respectively based on the relationships among the kinds and the characteristics (the first), and the interaction with the user (the latter). 
This research group decided thus to join these two different taxonomies and the result is shown in Table 2. This table actually represents the first step in the definition of the OSEL Taxonomy.

Table 2: Join of Wiley's and Redeker's Taxonomies

\begin{tabular}{|l|c|c|c|c|c|c|}
\hline \multicolumn{2}{|c|}{} & \multicolumn{5}{c|}{ Preliminary Taxonomy of the types of LO (Wiley) } \\
\cline { 3 - 7 } & Fundamental & $\begin{array}{c}\text { Combined } \\
\text {-closed }\end{array}$ & $\begin{array}{c}\text { Combined } \\
\text {-open }\end{array}$ & $\begin{array}{c}\text { Generative- } \\
\text { presentation }\end{array}$ & $\begin{array}{c}\text { Generative- } \\
\text { instructional }\end{array}$ \\
\hline \multirow{4}{*}{$\begin{array}{l}\text { Educational } \\
\text { taxonomy } \\
\text { (Redeker) }\end{array}$} & Receptive & $\begin{array}{c}\text { receptive } \\
\text { - basic }\end{array}$ & $\begin{array}{c}\text { receptive } \\
\text { - closed }\end{array}$ & $\begin{array}{c}\text { receptive } \\
\text { - open }\end{array}$ & $\begin{array}{c}\text { receptive- } \\
\text { expositive }\end{array}$ & $\begin{array}{c}\text { receptive - } \\
\text { didactic }\end{array}$ \\
\cline { 2 - 7 } & internally & $\begin{array}{c}\text { interactive } \\
\text { - basic }\end{array}$ & $\begin{array}{c}\text { interactive } \\
\text {-closed }\end{array}$ & $\begin{array}{c}\text { interactive } \\
\text { - open }\end{array}$ & $\begin{array}{c}\text { interactive - } \\
\text { expositive }\end{array}$ & $\begin{array}{c}\text { interactive - } \\
\text { didactic }\end{array}$ \\
\cline { 2 - 8 } & Cooperative & $\begin{array}{c}\text { cooperative } \\
\text { - basic }\end{array}$ & $\begin{array}{c}\text { cooperative } \\
\text { - closed }\end{array}$ & $\begin{array}{c}\text { cooperative } \\
\text { - open }\end{array}$ & $\begin{array}{c}\text { cooperative- } \\
\text { expositive }\end{array}$ & $\begin{array}{c}\text { cooperative- } \\
\text { didactic }\end{array}$ \\
\hline
\end{tabular}

Table 2 shows that the "join" of the two taxonomies create 15 different classes, among which many can not be considered valid by the research group.

Before giving a formal definition to the OSEL Taxonomy it is important to define and specify the terminological meanings in use, through the following glossary:

- Learning Object: any digital entity that can be used and re-used in a contest of technological learning (IEEE, 2001). In this case the re-usability is a fundamental ontological requirement for the definition of the LO, in spite of Wiley's classification;

- Metadata: it is a value that describes the history, the meaning, the quality and the destination of the data;

- Content: the data in the meaning of the previous definition of "Metadata";

- Element: every atomic unit which constitutes the "Content". It can be a text file, an image, and, anyway, it can be represented by a unique media;

- Combination of elements in a LO: the management of many elements or media within an interface of presentation;

- Interactivity of a LO: it is the possibility of a LO to refer to other internal or external elements by the action of the user (which is different from the interactive mode in an informatics system).

\section{The OSEL Taxonomy}

The aim of the OSEL Taxonomy is to classify the LO that can be used within a LCMS platform and, thus, only those LO that can be re-used. The distinction between Generative-Presentation and Generative Instructional is not important as it is connected to the subjective remarks of the author of the contents and, for this reason, can generate mistakes or difficulties in the classification of a repository. In the OSEL Taxonomy columns 4 and 5 of Table 2 have been deleted, as the distinction between LO having "Computergenerated instruction and / or practice" and "Domain-specific presentation strategies" is useless for the classification the group is working on. Table 3 represents the OSEL Taxonomy, which focuses on the intrinsic characteristics of the LO and the interaction with the user, and not on the remarks of the author on the contents, which can eventually be found by a semantic engine in the ADL/SCORM data once the LO has been classified. 
Table 3: The OSEL Taxonomy

\begin{tabular}{|l|l|l|l|l|}
\hline \multirow{2}{*}{} & & \multicolumn{3}{|c|}{ Preliminary Taxonomy of the types of LO (Wiley) } \\
\cline { 2 - 5 } & Receptive & Fundamental & Combined-closed & Combined-open \\
\hline \multirow{4}{*}{$\begin{array}{l}\text { Educational } \\
\text { taxonomy } \\
\text { (Redeker) }\end{array}$} & $\begin{array}{l}\text { Receptive - basic } \\
\text { B- simple }\end{array}$ & $\begin{array}{l}\text { receptive-closed } \\
\text { B- Passive }\end{array}$ & $\begin{array}{l}\text { receptive-open } \\
\text { B- Active }\end{array}$ \\
\cline { 2 - 5 } & Internally interactive & $\begin{array}{l}\text { Interactive- basic } \\
\text { T-simple }\end{array}$ & $\begin{array}{l}\text { Interactive-closed } \\
\text { T-passive }\end{array}$ & $\begin{array}{l}\text { interactive-open } \\
\text { T-active }\end{array}$ \\
\cline { 2 - 5 } & Cooperative & $\begin{array}{l}\text { Cooperative } \\
\text { basic } \\
\text { W-simple }\end{array}$ & $\begin{array}{l}\text { Cooperative- } \\
\text { closed } \\
\text { W passive }\end{array}$ & $\begin{array}{l}\text { Cooperative } \\
\text { open } \\
\text { W active }\end{array}$ \\
\hline
\end{tabular}

So far the types of LO individuated in the OSEL Taxonomy are nine:

1. B-simple: it is the derivation of the classifying combination of Fundamental (Wiley) and Receptive (Redeker). It represents a non-interactive LO, made up of a single content constituted by a single element, or a simple media. Group activities are not allowed. For instance: a JPEG image or a text.

2. B-Passive: the classifying combination of combined - closed (Wiley) and receptive (Redeker). It represents a non-interactive LO having a single content made up of at least two internal elements combined between them. Group activities not allowed. For instance: a JPEG image with textual description.

3. B-Active: the classifying combination of combined - open (Wiley) and receptive (Redeker). A non-interactive LO constituted by a single content made up of many internal and external elements combined among them. Group activities not allowed. For instance: a textual description connected to many JPEG images, among which at least one is on a http out of the platform.

4. T-simple: the classifying combination of basic (Wiley) and internal interactive (Redeker). An interactive LO constituted by at least two contents made up of a single element. Group activities not allowed. For instance: a web page containing only a text with hyperlink to another web page containing only a text and which is contained in the same LO.

5. T-passive: the classifying combination of combined - closed (Wiley) and internal interactive (Redeker). An interactive LO made up of at least two internal contents made up of at least two elements combined between them. Group activities not allowed. For instance: A web page with hyperlink to another web page contained in the same LO.

6. T-active: the classifying combination of combined - open (Wiley) and internal interactive (Redeker). An interactive LO constituted by many internal and external contents having many elements combined among them. Group activities not allowed. For instance: A web page with hyperlink to other web pages, among which at least one is on a http out of the platform.

7. W-simple: the classifying combination of basic (Wiley) and cooperative (Redeker). An interactive LO having at least two internal contents made up of a single element. Group activities allowed. For instance: A web page containing only a text with hyperlink to another web page in the same LO containing only a text and requiring a brainstorming activity through a communicative service available on the platform (i.e. forum, chat, video-conference).

8. W-passive: the classifying combination of combined - closed (Wiley) and cooperative (Redeker). An interactive LO constituted by at least two internal elements combined between 
them .Group activities allowed. For instance: A web page with hyperlink to another web page internal to the same LO and which requires a brainstorming activity through a communicative service available on the platform (i.e. forum, chat, video-conference)

9. W-active: the classifying combination of combined open (Wiley) and cooperative (Redeker). An interactive LO constituted of many internal and external elements combined among them. Group activities allowed. For instance: A web page with hyperlink to other web pages, among which at least one is a http external to the platform, and which requires a brainstorming activity through a communicative service available on the platform (i.e. forum, chat, videoconference).

\section{The Scenario}

The OSEL Taxonomy is useful in the organization of a heterogeneous repository of LO. The fitting of the repository can be made by external and extemporary contributions through a web form, in order to classify the contents according to the OSEL Taxonomy and to place them within the directory structure of the repository.

It is necessary that the compilation of the web form has to be made by the owner of the rights on the use and the distribution of the LO. The series of fields, with not null restriction, that can be conceptually divided into three areas:

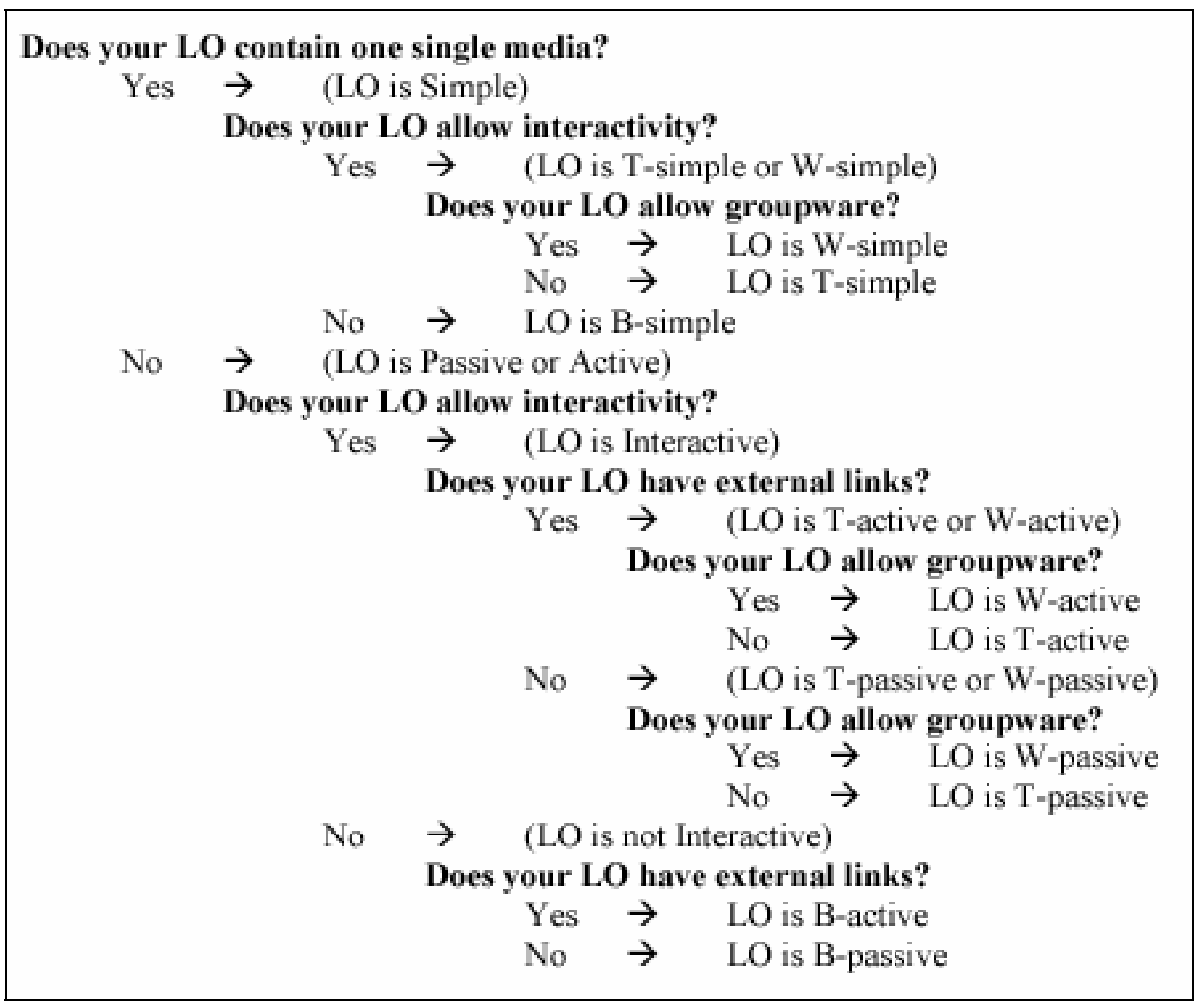

Figure 3: Logic scheme of guided questions 
- General Area: this area includes the fields LO name, LO Author, brief description of the LO

- Category Area: this section includes the fields LO Category and LO Target. The category field is an input of select kind, containing the categories approved by the OSEL Scientific Committee. The user can propose new categories upon registration and request to the OSEL Administrator. The target field is an input of select kind, containing the target of the potential addressee, always approved by the OSEL Scientific Committee. The user can propose new targets upon registration and request to the OSEL Administrator.

- Taxonomy Area: this section implies the compilation of several radioboxes to classify the LO according to the OSEL Taxonomy. The radioboxes perform in web the structure described in Figure 3

The image of the web form is visible in Figure 4.

The research group decided not to insert other questions as other kinds of information can be found through the introduction of an application on an intermediate level for the editing of the metadata, such as CLOMAT (Malaxa \& Douglas, 2005), and then of a software agent that is able to read the data contained in the metadata connected to the LO.

\section{Conclusions}

The planning of a good didactic project implies the attentive analysis both of the aims that are intended to be reached, and also of the tools that the internet technologies offer.

It is important to standardize with the aim of gathering contents coming from different sources. That is the OSEL Taxonomy mission: to standardize in order to guide the e-learning course designer.

The OSEL Taxonomy classifies the LO both through an ontological definition related to their domain of competence, and through the relationship that could eventually exist among them and the learners without delegating subjective opinions to the author. The extremely accurate construction of a glossary, based upon the re-usability concept as ontological requirement of the LO, make the OSEL Taxonomy particularly efficient for the classification of the LO that are used within the LCMS platforms.

The purpose is definitely practical: to classify in a standardized way in order to eliminate any ambiguity. As powerful side effect, then, the Taxonomy has the merit to clarify and to ask for a general consent about what is intended to be evaluated, or to decide which are the learning results to obtain, and finally to try to decide exactly what is meant to be submitted for examination. It is the definition of the educational aims that goes in line with the planning of the courses.

Perhaps in the future there will be a great crisis due to the inevitable integration in the School of the hypertext distributed on the Internet; this will produce a sort of cognitive dissonance between teacher and learner. Actually, the rigid division of knowledge into separate subjects contained in "schoolbooks", already shaken by the diffusion of the hypertexts, will be damaged by the awareness that knowledge is a social matter (and thus it is reticulate, rich of interrelationships), and then it implies the connection with other subjects also outside the lecture rooms. As a consequence, this awareness will clash with the paradigm established for centuries that the "book" is the heart of culture. On the contrary, the classification system can also be used within a search engine: the research of a word shows the results and the corresponding categories as well. 


\section{Osel Taxonomy}

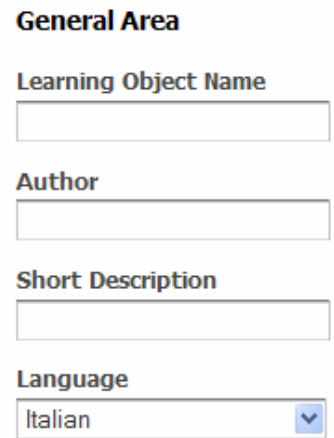

Submit Reset

Figure 4: Web form for the loading of the LO within the OSEL Repository 


\section{References}

Bloom, B. S. (1956). Taxonomy of educational objectives, handbook 1: Cognitive domain. New York: Longmans Green.

Chandrasekaran, B., Josephson, J. R., \& Benjamins, R. (1999) What are ontologies, and why do we need them? IEEE Intelligent Systems, 14(1), 20-26.

Cohen, E., \& Nycz, M. (2006). Learning objects and e-learning: An informing science perspective. Interdisciplinary Journal of Knowledge and Learning Objects, 2, 23-34. Available at http://www.ijklo.org/Volume2/v2p023034Cohen32.pdf

Convertini, N., Buonamassa, R., Marengo, A., Rossini, B., \& Scalera, M. (2005). The common creative licenses for a project of repository of learning objects. Fourth International Internet Education Conference, Heliopolis. http://www.distant-learning.net/

Gruber T. R. (1993). A translation approach to portable ontology specifications. Knowledge Acquisition, 5(2), 199220.

Gagne, R., Briggs, L. \& Wager, W. (1992). Principles of instructional design (4th ed.). Fort Worth, TX: HBJ College.

IEEE. (2001). Draft standard for learning objects metadata version 6.1. IEEE Learning Technology Standards Committee (LTSC).

Malaxa, V. \& Douglas, I. (2005). A framework for metadata creation tools. Interdisciplinary Journal of Knowledge and Learning Objects, 1, 151-162. Available at http://www.ijklo.org/Volume1/v1p151-162Malaxa28.pdf

Merrill, M.D., Li, Z. \& Jones, M. (1991). Instructional transaction theory: An introduction. Educational Technology, $31(6), 7-12$.

Nash, S., (2005). Learning objects, learning object repositories, and learning theory: Preliminary best practices for online courses. Interdisciplinary Journal of Knowledge and Learning Objects, 1, 217-228. Available at http://www.ijklo.org/Volume1/v1p217-228Nash.pdf

Neches R., Fikes R. E., Finin T., GruberT. R., Senator T., \& Swartout W.R. (1991). Enabling technology for knowledge sharing. AI Magazine, 12(3): 36-56.

Nelson, L. M. (1998). Collaborative problem solving: An instructional theory for learning through small group interaction. Unpublished doctoral dissertation, Indiana University.

Redeker, G. (2003). An educational taxonomy for learning objects. IEEE International Conference on Advanced Learning Technologies. Available at http://csdl2.computer.org/comp/proceedings/icalt/2003/1967/00/19670250.pdf

Richey, R. C. (1986). The theoretical and conceptual bases of instructional design. London: Kogan Page.

Varlamis, I. \& Apostolakis, I. (2006). the present and future of standards for e-learning technologies. Interdisciplinary Journal of Knowledge and Learning Objects, 2, 59-76. Available at http://www.ijklo.org/Volume2/v2p059- 076Varlamis.pdf

Wiley, D.A. (2000). Connecting learning objects to instructional design theory. A definition, a metaphor and a taxonomy. In D. Wiley (Ed.), The instructional use of learning objects, 1, 3-29 Bloomington, IN: AECT. 


\section{Biographies}

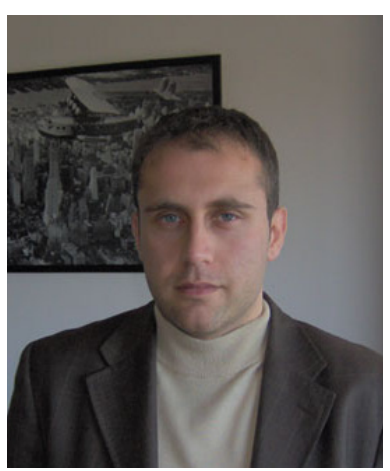

Nicola Convertini is Professor of Informatics at the University of Bari -Italy

I'm involved on the methodological comparison of CMS Open-Source, LMS platform, on the licensing of Learning Objects and on a methodology to evaluate Human Computer Interaction on web oriented application.

My areas of interest are around the impact of intelligent selection of Learning Objects in the corporate business strategy.

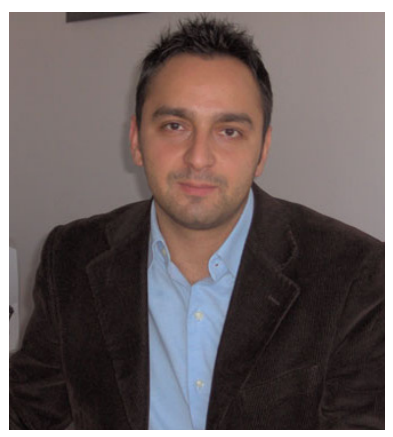

Diego Albanese is a lecturer in Computer Science at Bari University. I received my degree in Economic Sciences from Bari University in 2004.

My research interests include system development strategies; database development, networks administration and security; web database applications; data warehousing; data mining. Actually my main research interests are related to web-based learning and online education.

I'm co-author of articles in information systems planning and process and organizational innovation for main conferences.

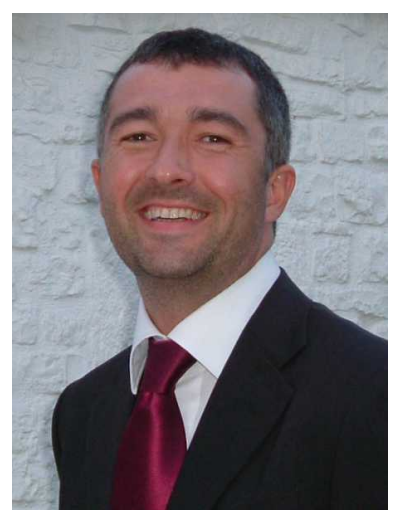

Agostino Marengo, Faculty of Economics, University of Bari - Italy.

My research activity as Assistant Professor in Faculty of Economics at University of Bari, takes place primarily on didactic methodologies implemented by the use of ICT tools, particularly the development of e-learning web-based platforms that compete to introduce the technologies of distance learning in traditional institutional campus courses and activities.

As coordinator of OSEL (Open Source e-learning research project, http://www.osel.it), currently my research plan is to create a database of Open Source LCMSs in order to choose and compare them. The research group is actually involved in usability, accessibility and quality evaluation of LMS (Learning Management Systems) and CMS (Content Management Systems) with a special goal to evaluate Open Source e-learning platforms. 


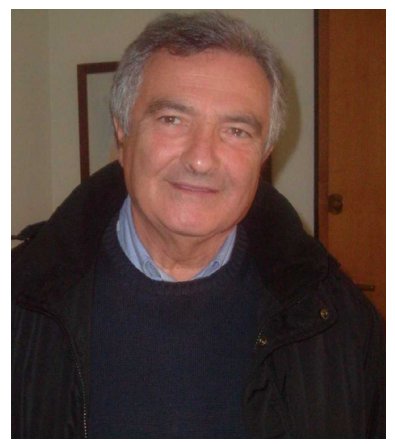

Vittorio Marengo, Faculty of Economics, University of Bari - Italy.

My research activity as Full Professor in University of Bari started with a research study on the analysis models of seismic waves data, in collaboration with Working Group Statistical Aspects of Seismicity inside European Seismological Commission (1972-1975).

Main research fields in my academic life are: Information Systems methodologies; optimization of models to transfer communication technologies; Database planning and design; Networking and Processing Systems; User-friendly tools for e-learning methodologies; Statistical methods for Data Mining.

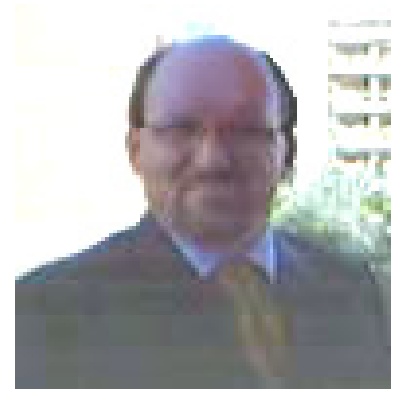

Michele Scalera since 1994 I've been an Assistant Professor of Information Technology at the Faculty of Economics at the University of Bari. I'm Ordinary Member of AICA (Associazione Italiana Calcolo Automatico). Recently I've been responsible for several projects at the University of Bari which include: Web Master of the Web Site of the Faculty of Economics, Director of the "Student Card Sub-Project of the Campus One European Project" for the introduction of the smart card. Responsible for the "On Line Enrollment of Exams" at the Faculty of Economics Scientific Component in the "Tempus Project JEP 24009-2003 European Project" with University of Sunderland, University of Irkutsk (Russia), University of Donetsk (Ukraine).

I'm author of three scientific books entitled "Evoluzione della tecnologia informatica: dal bit ad Internet" published in 2001, "Informatica" published in 1996 and "La Gestione dei dati in S.A.S." published in 1994 